\title{
The Emergence of Clinical Practice Guidelines
}

\author{
GEORGE WEISZ, ALBERTO CAMBROSIO, \\ PETER KEATING, LOES KNAAPEN, \\ THOMAS SCHLICH, and VIRGINIE J. TOURNAY
}

\author{
McGill University; University of Quebec; UMR PACTE (CNRS)
}

Clinical practice guidelines are now ubiquitous. This article describes the emergence of such guidelines in a way that differs from the two dominant explanations, one focusing on administrative cost-cutting and the other on the need to protect collective professional autonomy. Instead, this article argues that the spread of guidelines represents a new regulation of medical care resulting from a confluence of circumstances that mobilized many different groups. Although the regulation of quality has traditionally been based on the standardization of professional credentials, since the 1960s it has intensified and been supplemented by efforts to standardize the use of medical procedures. This shift is related to the spread of standardization within medicine and especially in research, public health, and large bureaucratic health care organizations.

Keywords: Practice guidelines, standards, regulation, health policy.

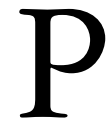

RACTICE GUIDELINES TELLING PHYSICIANS HOW TO do their jobs better are now common throughout the Western world. The National Guideline Clearinghouse, created by the U.S. Agency for Healthcare Research and Quality (AHRQ), currently lists on its website more than two thousand guidelines (as of October 17, 2006). Some critics worry that this profusion of guidelines will inappropriately routinize medical work and lower the quality of practice. But research has

Address correspondence to: George Weisz, McGill University, Department of Social Studies of Medicine, 3647 Peel Street, Montreal, Quebec, Canada H3A 1X1 (email: george.weisz@mcgill.ca).

The Milbank Quarterly, Vol. 85, No. 4, 2007 (pp. 691-727)

(c) 2007 Milbank Memorial Fund. Published by Blackwell Publishing. 
shown that even though guidelines are modestly effective in changing practices, many practitioners do not follow them. Accordingly, a growing literature seeks strategies for improving their compliance.

The spread of clinical guidelines is usually explained in one of two ways. First, guidelines have been imposed on physicians by politicians and administrators as a response to rising health costs. This is hardly a new perspective, as budgetary constraints were invoked in one of the very first analyses of guideline development (Fowkes and Roberts 1984) and reappear regularly (e.g., Durand-Zaleski, Colin, and Blum-Boisgard 1997). In France, administrators of the health insurance system believe that through guidelines, reimbursement strategies, and incentives, they can save 6 billion euros annually by modifying the ways in which doctors practice medicine (France Cour des comptes 2005).

Another explanation is that physicians themselves have prepared most of the guidelines in an attempt to preserve their professional autonomy in the face of administrative pressures or as a way for groups or institutions to compete in the marketplace (Castel 2002; Day, Klein, and Miller 1998; Timmermans and Kolker 2004). Using this framework, analysts explore the tension among professional groups, between collective professional autonomy and the individual practitioner's clinical autonomy (Armstrong 2002), or, from an epistemological perspective, the relationship between disciplinary-expert and mechanicalquantitative forms of objectivity and authority (Berg et al. 2000; Schlich 2007).

In this article, we suggest a third way to conceptualize the rise of guidelines: as a change in the method of regulating the quality of medical practice. (By regulation, we mean not just the rules and norms produced by governmental and professional organizations but also the less formal conventions and standards established in order to make possible many different kinds of collective activities.) Although guidelines themselves are not new, we argue, the proliferation of collectively produced guidelines since the 1980s represents a growing effort to bring order and coherence to a rapidly expanding and heterogeneous medical domain. Furthermore, this proliferation of guidelines is the product of multiple groups of actors arrayed in novel permutations and combinations that cannot be reduced to a simple dichotomy between physician and administrator. In the following, we describe how this transformation took place. 
Until the 1970s, medical actions were indirectly regulated through the training and credentials guaranteed by both the organized profession and state authorities. Armed with these credentials, individual physicians were assumed to be competent enough to determine the appropriate medical procedures. Although the opinions of experts, expressed informally or formally, supplemented educational credentials and provided some guidance for practice, they were either diffused narrowly or had little formal status. In contrast, the regulation of quality now explicitly targets medical practice itself by attempting to modify physicians' behavior. Like the regulation of credentials that it supplements rather than replaces, numerous groups and institutions are involved in this process.

This article explains how the standardized credentials granted by recognized medical schools or state authorities came to be perceived as an insufficient guarantee of quality. We suggest that even though key developments took place at a specific time (the 1960s and 1970s) and place (the United States), guidelines have a longer international history, which is associated with the spread of numerous complex activities in health care that are thought to require standards in order to function appropriately. According to the analytical language developed by Timmermans and Berg (2003, pp. 24-26), procedural standards that specify the actions or protocols that must be followed in given situations have recently assumed special significance. But for more than a century, procedural standards have accompanied and have depended on the development of (1) design standards that define the elements of complex systems of action and allow them to function, (2) terminological standards that fix the terms classifying and describing phenomena and permit their comparison, and (3) performance standards that define outcomes or results acceptable in particular contexts. While we can say with the benefit of hindsight that these three forms of standardization have produced the common classifications, entities, and measures that enable collective negotiation about appropriate practice, we also must recognize that historical actors did not always distinguish among the different standards that they frequently pursued simultaneously.

We contend that procedures were standardized at three interrelated levels. First, outside the traditional private relationship between doctor and patient were the large-scale institutional settings for biomedical practice that were not necessarily controlled by physicians. There, the standardization of classifications, measures, and procedures was 
perceived as a requirement for a variety of purposes, including the evaluation of outcomes, large-scale organizational activity, and, later, thirdparty payment. Beginning in the nineteenth century, public health was one such domain. Then, in the twentieth century, public health standards entered the world of clinical medicine as preventive public health expanded to the sphere of therapeutics through such mechanisms as sexually transmitted disease, tuberculosis, and cancer control programs. Hospitals, which grew at a prodigious rate at the end of the nineteenth century, also generated demands for standardized organizational structures, practices, and data collection.

Second, the results of medical research vastly complicated the world of medical practice and its regulation. Starting in the early twentieth century and accelerating after World War II, the expansion of research created new problems in translating this knowledge into better health care. Efforts to determine collectively the efficacy of so many new products and procedures intensified long-felt needs to standardize classification categories, instruments, measures, and research protocols. Just as the standardization of public health eventually influenced medical practice, testing protocols frequently found their way into clinical practice in such technically sophisticated fields as cancer research. Finally, research has produced many new and increasingly complex procedures and instruments that cannot be used effectively without elaborate protocols.

Third, after World War II, the private relationship between doctor and patient became part of a public realm that was subject to new forms of bureaucratic control, rationality, and knowledge. This was one consequence of the postwar expansion of the government's role as a provider or purchaser of health services and as a guarantor of the public's health. In this context, practice variation became increasingly problematic, an indication that someone was doing something wrong. This knowledge of variation was an outcome of the new information about health systems, the production of which created yet greater need for standardized classifications, measures, and entities. The complex mechanisms introduced to monitor, evaluate, and improve health care practices also demanded elaborate guidelines.

These processes converged at the end of the 1960s and have intensified and evolved ever since. Together, they have produced the culture of clinical practice guidelines. Although these developments crossed the globe, they occurred first and foremost in the United States before being 
adopted in much of the Western world in the 1980s. For that reason, we discuss international developments with especially close attention to the American experience.

\section{The Standardization of Physicians' Credentials}

Concern that healers meet minimal standards has existed for centuries; indeed, some historians trace it back to the medieval university (Bullough 1966). During the early modern period, competence was usually regulated at the local level, with medical guilds and municipal authorities sharing this responsibility in different ways in different locales. The groups involved may have had different reasons for imposing such standards: public authorities might have wanted to minimize social harm or to make manifest their own powers and/or reward loyal servitors; or groups of practitioners might have tried to impose or protect monopolies of teaching or practice by couching demands for mandatory diplomas or licenses in the language of customary and legal privilege as well as competence. The culmination of such practices was medical licensing at the national or regional levels. This was imposed either by the state, as in the case of France in the early nineteenth century (but which required doctors and medical professors to implement) or as the result of campaigns by medical professions seeking to improve their quality and status, as in the United States during the last decades of the nineteenth century (but which required the active intervention of state authorities). Sociologists and historians have traditionally regarded licensing as part of the professionalization process through which occupational groups have come to monopolize certain practices (e.g., Freidson 1970; Johnson 1972; Larson 1977). The fact that licensing was usually justified by public health considerations and that it constituted a form of regulation has received less attention.

Licensing involved the imposition of minimal standards of competence that could always be raised by changing the conditions of licensing or by reforming medical education. From roughly 1880 to 1914 , medical curricula throughout the Western world were restructured during a particularly intense period of reform, according to what were deemed the demands of modern science (Bonner 1995). By the 1920s, medical knowledge and practice had become so specialized that general medical 
licenses no longer seemed adequate. Accordingly, formal specialty training and certification, yet another de facto form of licensing, was introduced during the interwar and postwar years (Weisz 2006). But even this did not guarantee competence as biomedical knowledge, procedures, and products continued to proliferate.

Under such conditions, no program of training or certification could take account of every possible condition, situation, or innovation. Although a variety of methods to transmit expert knowledge to physicians were available, the most common was the expert paper published in a major medical journal or presented at a medical meeting advising practitioners on how best to manage a situation or condition. For the minority of doctors working in institutions like hospitals or dispensaries, it also was possible to learn new skills, procedures, and approaches from colleagues. Surgeons went to great lengths to organize and formalize the acquisition of tacit knowledge. Among other things, they set up surgical travel clubs (Wangensteen 1978; Wilde 2004) and established hands-on courses and fellowship programs (Schlich 2002) to disseminate new techniques. All these modalities left doctors largely free to pick and choose from the information and skills available.

The expansion of regulation beyond the quality of practitioners to the quality of medical acts and the formalization of expert advice was a radical shift, for two reasons. First, even though expert counseling was perceived to be purely advisory, the advent of collectively produced guidelines, even when lacking formal regulatory force, had considerable moral authority and thus presented a potential challenge to individual freedom of medical choice. The physician's autonomy to evaluate, judge, and tailor therapy to the individual patient was deeply ingrained in the ideology of the medical profession, a consequence of the formal certification that distinguished its members from their many competitors. In the nineteenth and early twentieth century, moreover, therapeutic individualism was promoted by the very nature of medical practice. With relatively few therapeutic modalities at the physician's disposal, the art of medicine consisted precisely of individualizing therapy for each particular case.

Second, apart from the defense of professional autonomy, the collective production of clinical practice standards was fraught with difficulties in the absence of sufficiently developed design, terminological, and outcome standards. A consensus on them could not emerge until medical leaders and academic elites had at least agreed on the units being 
discussed and the criteria used for discussing them. This process took more than a century.

\section{Standardization in the Public Sphere}

In both the United States and Europe, many medical decisions before the 1960s were confined to private practice and thus were left to physicians and their patients. During this same period, however, doctors had less than full autonomy in public sectors of medical practice and so were subject to various organizational imperatives for standardization. Chief among these was public health. Because those directing public services needed information about the areas under their jurisdiction, one of the first to be standardized was public health data. Basic categories had to be defined and standardized in order to be useful, and doctors were constrained in a variety of ways - through standardized forms and/or instruments - to provide data that were both uniform and comparable. ${ }^{1}$

Some of the most important efforts at standardizing terminology took place at the international level. A series of conferences during the $1850 \mathrm{~s}$ produced an international nomenclature of causes of death (revised periodically thereafter), which was necessary to produce accurate and comparable mortality statistics (Fagot-Largeault 1989). While discussing a difference of opinion about principles of classification during these early conferences, the French statistician Jacques Bertillon emphasized how unimportant such principles were when the goal was only to create conventional categories that permitted comparability. Rather, "what is important is not that the classification be perfect, but that the morbid categories counted by statistics be always the same" (Bertillon 1895, p. 202, our translation). Occasionally, procedural rather than terminological standardization was the goal. Murderous epidemics definitely fell into the public sphere, and doctors as well as citizens were urged to act in the ways prescribed by public authorities, who published instructions on how to deal with sporadic epidemics like cholera and yellow fever (Boston Board of Health 1855; College of Physicians of Ireland 1853; Health Commissioners Boston 1832).

At the turn of the twentieth century, public health expanded to include endemic diseases like tuberculosis (Bryce 1894; Framingham Community Health and Tuberculosis Demonstration 1918; National Tuberculosis Association 1920) and sexually transmitted diseases (Buchen 1917; 
Massachusetts Department of Public Health 1931). Large programs were created to prevent and treat these diseases, and each issued administrative imperatives for more standardized practices of classification, prevention, diagnosis, and, increasingly as we shall see, treatment. Child health programs also constituted an important domain of public health activity and practice standards (Chicago Community Trust 1922; U.S. Children's Bureau 1934, 1943). During the interwar years, new forums for standardization emerged at the international level. The League of Nations' health committee and subcommittees, for instance, promoted the international standardization of nomenclature, statistical methods, epidemiological databases, definitions of biological agents, and, through training programs, public health personnel (Dubin 1995; also see Mazumdar 2003).

During this period, the public domain of medicine also reached into therapeutics. With the development of effective therapies like Salvarsan for syphilis and radium therapy for cancer, public health programs now frequently included a therapeutic component. After the turn of the century, as cancer became increasingly subject to state and professional concern, cancer control programs actively promoted early detection and treatment and increasingly blurred the distinction between public health and clinical medicine (Cantor 2007; Pinell 2002). Like the programs to prevent $\mathrm{TB}$, cancer-care programs deployed new technologies that were complex and sometimes dangerous, notably the use of $\mathrm{x}$-rays and radium, and that required guidelines and protocols for their safe and effective use (Dommann 2006; General Recommendations of the National Laboratories 1934; Roentgen Society 1915). New diagnostic laboratory tests also required elaborate instructions (Holman et al. 1918). Despite the wellknown ideological differences between practitioners of public health and those of clinical medicine, historians argue that public health in several nations during this period abandoned its traditional environmental orientation in favor of a more narrowly medical vision that focused on screening and early intervention (see the essays in Porter 1994).

By the early twentieth century, other therapeutic institutions as well were becoming targets for rationalization and standardized procedures. Chief among these were hospitals, to which much private medical work had been transferred. As large organizations, hospitals required their own forms of coordination and standardization, made all the more necessary by the growing "task interdependencies" (Gosselin 1985). In the United States, where the number of hospitals was expanding at a frenetic 
pace (Stevens 1989), one reaction was the hospital efficiency movement, seeking to "weld scientific management or ... industrial efficiency techniques, to medicine” (Reverby 1981, pp. 161-62; also Howell 1995). This movement aimed to provide hospitals with standardized administrative and medical procedures that met the new criteria of efficiency but had only a minor impact.

More limited local efforts met with greater success. In 1912, for example, the Associated Out-Patient Clinics of the City of New York, a corporative organization of twenty-six dispensaries and hospital outpatient departments, was established. This organization published standards for its member institutions that dealt with "space requirements, personnel, the kind of patients to be treated, record keeping and history taking, the average time per physician with new patients and return cases, facilities for laboratory and x-ray examinations and for physical therapy, as well as the place of social service, visiting nursing and patient education" (Rosen 1976, p. 39). Such standardizing tendencies were fueled by the growing intervention of third-party payers, including municipal authorities and local charitable groups, outside the doctor-patient economy. In the German-speaking countries, insurance companies created their own hospitals to deal with work-related accidents, in which rigorous procedural standards were established for surgeons (Eghigian 2000; Schlich 2002). Thus by the early twentieth century, procedural standardization was at least attempted, often with some degree of success, in a number of organizational contexts.

\section{Private Medical Practice Enters the Public Arena}

Beginning in the early twentieth century, traditional private medical practice in almost every nation began to face increasing pressures for standardization. The numerous innovations resulting from the expansion of medical research created serious dilemmas even as they offered physicians new therapeutic tools. Individual clinical judgment was becoming visibly inadequate to the task of evaluating the effects of so many new products and therapies. How were clinicians to determine the dangers to patients and, in the case of new technologies like x-rays and radium therapy, to those who applied them while simultaneously developing the relatively complex protocols necessary for their effective and safe use? Some pharmaceutical manufacturers took matters into their 
own hands, delegating products like insulin to networks of experts who tested their efficacy and worked out optimal doses and timing (Sinding 2002). In countries like France, where state institutions like the Academy of Medicine had handled relatively simple regulations in the nineteenth century, efforts were made to adapt to new products like biological serums (Weisz 1995). But the recognition that new sorts of governmental agencies were needed was widespread. These pressures were intensified by controversies over the efficacy of innovations like Paul Ehrlich's sera (Gradmann and Simon 2008) as well as major medical-legal scandals like the Lübeck trial (Bonah, Lepicard, and Roelcke 2003). In the United States, where the medical profession jealously guarded its prerogatives against state power, professional organizations initially undertook some of these tasks until public agencies were established.

Attempts by medical societies to reach collective conclusions that would help direct medical practice sometimes provoked deep hostility because they appeared to challenge individual medical autonomy (Marks 2006). They also were not notably successful, given the lack of agreement about methods for achieving consensus. The efforts of an international commission of the League of Nations during the 1920s to reach consensus about the radiological treatment of cervical cancer exemplify the difficulties of producing collective guidelines at a time when clinical science itself remained largely unstandardized. The initiative began with an attempt to compare results in three major clinics using different methods of radiation therapy. The comparison came to a halt, however, when it became clear that neither diagnosis nor reporting in the three centers could be compared. The chief outcome of the committee's efforts was the development of standardized forms and categories for recording treatment and results (Radiological Treatment of Cancer 1929).

Some efforts at standardizing cancer nomenclature and classificatory categories made during the interwar period were immensely successful and became crucial to the later conduct of cancer clinical trials. In 1930 the Radiological Commission of the Health Organization of the League of Nations published a report proposing the subdivision of cervical cancer into stages based on the anatomic extent of growth; this became known as the League of Nations Classification for Cervical Cancer, which continues to be revised and updated. ${ }^{2}$ At the Cleveland Clinic in the late 1930s and early 1940s, an American surgeon, U.V. Portmann, devised a similar classification system for breast cancer (Nachlas 1991). In an entirely different domain, private American and British organizations 
collaborated during World War II to standardize blood pressure measurement (American Heart Association 1941). Such efforts were important prerequisites to the eventual development of practice standards.

The American medical profession, individualistic and powerful enough to defeat efforts to create national health insurance for many decades, was especially active in standardizing certain aspects of medical practice. Political decentralization, geography, and a rapidly growing population and economy produced unique conditions for creative intervention by the American medical profession, seconded by vigorous private associations and public health agencies. The various activities of representative professional bodies in the United States make clear the difficulty of disentangling issues of professional competence from those of standardization at the levels of scientific classification and methodology, medical practice, or organizational structure. All these domains faced similar challenges in managing and coordinating increasingly large numbers of individuals, products, techniques, and equipment.

The American Medical Association (AMA), it is well known, was central to regulating practitioners' credentials by standardizing American medical education in the early twentieth century (in collaboration with major foundations), introducing state licensing (with the help of state legislatures), and contributing to the establishment of a system of specialist certification after 1920 (in collaboration with specialist associations). Less widely known is the AMA's early attempt to evaluate a growing number of therapeutic products through clinical research. In 1905 the AMA established the Council on Pharmacy and Chemistry to analyze the composition and quality of new drugs, with the results published in its Journal of the American Medical Association. These standards formed the basis for the revised federal drug regulation introduced during the 1930s (Marks 1997, 2006). ${ }^{3}$ During the interwar years, the AMA also began evaluating the plethora of electrical instruments arriving on the market and tried to control diagnostic testing by recommending laboratories for doctors and hospitals to use (Weisz 2006).

In some ways, the standardization work of the American College of Surgeons (ACS) was even more remarkable. Its creation in 1917 served as a model for the other American specialties that followed the path of specialist certification. The college also began standardizing practices through therapeutic evaluation, assessing cancer therapies on the basis of case records, and periodically publishing results (American College of Surgeons 1931b). Like the international agencies just cited, the ACS also 
standardized terminology. In the early 1920s, it formed a committee to register bone sarcoma that developed a standard nomenclature for bone tumors under the direction of one of the most radical figures of the hospital efficiency movement, Ernest Amory Codman (Codman 1925). Also in the early twentieth century, the ACS spearheaded a campaign to impose minimum standards on the growing number of American hospitals (Stevens 1989).

The ACS's campaign included the publication of a small number of formal, professionally produced guidelines, leading the way in 1931 with two publications. One of them set the guidelines for organizing cancer services in hospitals. In addition to suggesting how best to organize these technically complex services, the document emphasized the role of institutional standardization as a prerequisite for producing uniform and comparable results in clinical research (American College of Surgeons 1931b). That same year the ACS produced a manual of fracture care (American College of Surgeons 1931a). In 1938 the American Academy of Pediatrics produced practice guidelines regarding immunizations for children (Margo 2004). This professional activism in the United States created usable precedents and models for further action. In subsequent decades, such regulatory activity accelerated, making the United States the first country to develop practice guidelines on a significant scale.

A number of features characterized these early international and American efforts at guideline and protocol development. First, a variety of groups were involved: public health agencies at various levels, state and national governments, private associations devoted to specific diseases, and medical societies of all sorts, with occasional instances of real collaboration among them. Second, although creating guidelines for practice occasionally was possible, the result frequently was the standardization of categories, measurements, and instruments to produce reliable knowledge. Third, the attempt and failure to produce effective procedural guidelines sometimes led to the standardization of design and terminology.

This American model of standardization by professional associations was only one model for transforming health care. The British government, by contrast, used a very different approach when establishing the Radium Trust and the Radium Commission in 1929, with the former buying radium on a large scale and the latter distributing it to hospitals. These bodies thus were able to tie the distribution of radium to the hospitals' adoption of specific standards of therapeutic practice and, in the 
process, had a major impact on the structure of cancer therapy nationally (Cantor 2007). The production of voluntary guidelines by professional associations or disease-prevention groups probably seemed particularly urgent in the United States precisely because of the absence of centralized bodies authorized to impose procedural standards.

\section{The Spread of Guidelines during the Postwar Years: A Bird's-Eye View}

After World War II, all aspects of the medical enterprise expanded dramatically, especially in the United States, which by then was the world's richest nation and the most profligate spender on health care. Everywhere but in the United States, national health insurance systems were established or significantly extended. Hospitals everywhere were expanded and modernized. The research sector grew significantly as well, especially in the United States, where government funding rose to unprecedented heights. According to Daniel Fox (1996), total research spending in American medical schools, adjusted for inflation, grew almost fiftyfold between the postwar years and 1993, with the federal government providing about 75 percent of the funds through the National Institutes of Health (NIH). Pharmaceutical companies contributed additional funding that eventually surpassed the NIH's (Cook-Deegan and McGeary 2006). This expansion of both public domains of medical practice and biomedical research, with their attendant multiplication of standards and protocols, made the standardization of medical procedures appear both feasible and imperative.

The expansion of biomedical research had a variety of consequences. First, it vastly augmented the already large number of technological and pharmaceutical innovations with which doctors and growing numbers of administrators had to cope, and it amplified the pressure for collective forms of evaluation. Second, many large domains of research became sufficiently collaborative to generate standards and protocols. In particular, the spread of multicenter research required standardized categories and practices that allowed for the aggregation of data. This happened first in several biomedical domains whose interactions among many researchers, complex technologies, clinics, and laboratories necessitated some form of negotiated conventions, which we have termed elsewhere as regulatory objectivity (Cambrosio et al. 2006). Cancer treatment was a notable 
case in which research and clinical practice were closely associated. Here, chemotherapy was increasingly the result of research protocols that had become routine practices. Funding agencies demanding comparability of results forced researchers in other specialties to follow this path as well. Indeed, one of the motivations for the development of the Diagnostic and Statistical Manual of Mental Disorders (DSM) III was to establish disease categories stable enough to be the subjects of rigorous and fundable research (Healy 1997; Wilson 1993). Third, randomized clinical trials (RCTs) gradually became a "gold standard" for evaluating therapies (Marks 1997). Despite the controversies continuing to surround them (e.g., Nowak 1994), RCTs were widely believed to tell us, in many cases, what best practice was. The logical conclusion for many has been that practices differing from those validated by RCTs are mistaken deviations from correct clinical procedure, and that the perceived solution is to diffuse knowledge of correct practices in various ways, including practice guidelines.

The expansion of biomedical research had yet another consequence: it brought into the open some of the ethical dilemmas long associated with research on humans, and it also created new ones as technology expanded the frontiers of the possible. A substantial minority of the "guidelines" published during the 1960s and 1970s dealt with issues ordinarily categorized as "bioethical" concerns, including the standardization of informed consent requirements. The products of medical research created a variety of ethically complex conditions and practices in clinical medicine-such as brain death, life-sustaining technologies, and in vitro fertilization - which seemed to require ethical guidance to supplement their very complex technical guidelines (Rothman 1991). These guidelines then became integral parts of the protocols defining these activities (Tournay 2006). Today, the very work of ethics is itself becoming subject to special guidelines ${ }^{4}$ and evidence-based research.

If the consensus necessary to produce guidelines was made possible by new techniques like randomized clinical trials or the Delphi method developed at the Rand Corporation to generate forecasts from experts, it was made necessary by perhaps the most significant development of these postwar years: the increasing role of governments in every aspect of health care. Through the national health insurance systems that were established during the postwar years in much of the Western world, including the partial system developed in the United States in the mid1960s, medical practice became integrated into the public political arena 
and transformed into an object of intense media scrutiny. Public accountability became a critical issue (Wiener 2000). In this context, guidelines produced by experts are attractive for many reasons. All health insurance systems must decide what counts as diseases and medical procedures, which of these are to be paid for, and who should be paid for doing them. This is not an exercise in finding truth. Rather, it requires negotiations in which many actors make claims in the name of various values and rights. What is important in the end is that an act can be placed into one category or another to be dispatched accordingly. Such pigeonholing is frequently performed by administrative fiat or negotiation. (For the way this worked in the German insurance system, see Ruger and Bell 2004.) But this leaves politicians vulnerable to public criticism. If expert guidelines can be invoked to support these decisions, this helps depoliticize these issues (Jasanoff 1990; Nelkin 1995).

An equally important rationale was the perceived need in nearly all Western nations to impose rational direction and coordination on an array of institutions-hospitals, dispensaries, medical schools, local medical assistance or insurance programs - that had been created incrementally and almost haphazardly over long periods of time and that were increasing in both size and technological-functional complexity. This need was in part, but only in part, linked to budgetary considerations. It also was associated in many European countries with the belief by many administrators and politicians that medical professions were too powerful and needed to be brought down a peg or two (Hassenteufel 1997). Less often emphasized but no less critical was the fact that these different kinds of medical institutions were now lumped together in large administrative structures, becoming parts of "systems" that did not seem to function in any obviously comprehensible way. They appeared to require reorganization based on "rational" principles (e.g., for reorganization of the British National Health Service, see Fox 1986; Webster 1988) and some guarantee of "quality" (Robelet 2002). Not only did all sorts of practices require standardization, but administrators also required information about health "systems" in order to exercise organizational control. This information then had to be available in standard quantified form, allowing for understanding and evaluating activities along various axes. In turn, this created health organization research, which received a fraction of the funding for biomedical research (Gray, Gusmano, and Collins 2003) and deployed quite different forms of disciplinary expertise, including economics and organizational science (Benamouzig 2005; Fox 
1979). But health services research engendered further efforts to ensure comparability through the standardization of categories, methods of data collection, and practices under study that do not differ in kind from similar efforts in the biomedical research sector.

\section{Guidelines in the United States: Continuity and Change}

During the postwar years, the modest production of guidelines in the United States continued and gradually accelerated. A review of major library catalogs found twenty such guidelines published between 1945 and 1959 and thirty-five between 1960 and $1974 .^{5}$ This sample certainly is incomplete, however, because undoubtedly some guidelines circulated without being cataloged by libraries, but they nonetheless give us some idea of the activities that provoked collective efforts at guidance.

The vast majority of the cataloged guidelines were American, with a sprinkling of British contributions. This may simply be an artifact of the available search engines, since it is quite clear from the titles that some collective guidelines were produced in a few European countries. Nonetheless, it is likely that the United States did produce most of these guidelines. Many had an administrative objective and frequently targeted the expanding hospital sector-such as setting up a complex program, ward, or structure-and/or the proper relations between personnel, like doctors and nurses (e.g., Indiana Polio Planning Committee 1950; Physicians' Guidelines 1966). The new insurance system generated various sorts of guidelines (e.g., Committee on Insurance and Prepayment Plans 1965), as did the spread of large public health programs (e.g., Guidelines for Organizing State and Area-Wide Community Health Planning 1966). As in earlier decades, the standardization of categories and records in order to make data comparable remained a priority (e.g., American Association of Medical Record Librarians 1957; American Urological Association 1968).

The number of guidelines and manuals dealing with diagnosis and treatment grew as well. Military medicine, and especially health care for veterans, was a sector in which bureaucratic imperatives (and a firm sense of hierarchy) generated early guidelines about tuberculosis treatment (U.S. Veterans Administration 1949). In fact, most of these early guidelines dealt with traditional concerns like tuberculosis (e.g., National 
Tuberculosis Association 1955), newborns and children (e.g., American Academy of Pediatrics 1949, 1955), and cancer (e.g., American College of Surgeons 1970; Iowa State Medical Society 1948). But relatively new subjects for guidelines appeared as well, including rehabilitation, coronary disease, sports medicine, and anticoagulant therapy (e.g., American College of Obstetricians and Gynecologists 1959; American Heart Association 1962; Brussels Treaty Organisation 1955).

From the mid-1970s on, the production of guidelines intensified and became subject to extensive comment and discussion. ${ }^{6}$ Between 1975 and 1984, guidelines were produced in many different countries, suggesting that the pressure for their spread cut across national borders. Several guidelines drawn up by international health organizations like the World Health Organization (WHO) reflected the increasing globalization of public health activities. The United States nonetheless continued to produce the majority of guidelines, in an effort to come to terms with the rapid transformation of the American health care system.

Most of the pressures faced by American medicine were typical of those of all developed nations, as suggested in the previous section. But the conditions under which these pressures were faced were different. Medicare and Medicaid were introduced during a period of rapid institutional expansion as well as radical changes in medical practice generated by a huge investment in biomedical research and technology. Unlike European countries, the United States did not have several decades to develop stable and centralized institutions governing health care and was not in a position to cope with these changes. In fact, power in the U.S. health care system was notably fragmented.

One consequence, as virtually all studies of American medicine have noted, was rapidly escalating costs. Some efforts were made during the 1950s to introduce "utilization review" practices in order to control inappropriate or unnecessary hospital services. But the huge increase in state and federal spending for personal health services from 22 to 40 percent between 1960 and 1980 made the control of these services critical. Numerous strategies were implemented, and many institutions and agencies (some short-lived) were created ${ }^{7}$ to guarantee accountability and the appropriate use of medical resources (Institute of Medicine 1989; Wiener 2000). Professional standards review organizations (PSROs), established by amendments to the Social Security Act in 1972, played an especially important role in developing data systems permitting the comparison of practice patterns. They also led to classification 
schemes and practice guidelines (Gray 1991; Institute of Medicine 1989).

Such efforts culminated in 1989 in the establishment of the federal Agency for Healthcare Research and Quality (AHRQ) with a mandate to produce practice guidelines (Gray, Gusmano, and Collins 2003). Cost containment was only one of many concerns that suggested the need for utilization review. New data (including some produced by the PSROs) revealed alarming discrepancies, institutional as well as regional, in the incidence of medical and especially surgical procedures. This lent credence to the view that neither money nor health care was being distributed wisely. New knowledge about practice variations, produced and analyzed over several decades by John Wennberg, was especially influential (e.g., Wennberg 1979; Wennberg and Gittelsohn 1973; for Wennberg's own views, see Mullan 2004). He and others who questioned the appropriateness of certain medical practices challenged the notion of a universal medical science and raised serious quality issues (McPherson and Bunker 2006). Such work was supplemented by questions raised by Archie Cochrane's influential book Effectiveness and Efficiency, about the scientific validity of many widely diffused current medical procedures (Cochrane 1972). Variation had come to be seen as something to be remedied.

But evaluation of variation and appropriateness of medical procedures implied the existence of a consensus on appropriate practice standards. How was this to be achieved? Although organizations devoted to utilization review were not necessarily very clear about the criteria they used (Gray 1991), they did have a number of available options. If existing practices were quantified, practices diverging from statistical norms might then be considered inappropriate. Or one could rely on expert opinion, although this raised the question of the representativeness and quality of such expertise. One solution was to try to tighten the existing collective forms of provider-based peer review. Accordingly, in 1982 Congress replaced PSROs with PROs, "statewide quality control peer review organizations," and a few years later mandated PROs to manage a second opinion program (Institute of Medicine 1989). Another possibility was to use the expanding research establishment to define correct practice. One of the consequences of the massive American investment in biomedical research was Congress's understandable expectation that, as we shall see, national research agencies like the NIH would play a more prominent role in improving the quality of medical practice. 
A third possibility was for medical associations to become actively involved in producing standards. Much of the information about practice variation was generated by physician-controlled organizations like PSROs, and medical participants were as shocked as anyone by the results. The growing conviction that much medical care was inappropriate and unnecessarily expensive increased the influence of nonphysicians in determining medical practice through insurance reimbursement and also threatened the scientific status of American medicine. Adding to American physicians' sense of crisis during the second half of the twentieth century was the growing hostility to the power and affluence of the medical profession. This was reflected in such varied phenomena as the writings of Ivan Illich characterizing medicine as iatrogenic, the work of Thomas McKeown and others questioning the health benefits of greater spending on health care, the growing popularity of alternative medicine, the women's health movement, and the litigious impulse that has made malpractice insurance so expensive in the United States.

One consequence of this crisis was the intensification of concerns about practitioners' competence. Marc Berg has documented how editorialists in medical journals during these decades framed the problem of the perceived inadequacies of medical practice (Berg 1995, 1997). During the 1970s and 1980s, specialist associations-led by the example of the newly established field of family medicine-began instituting the periodic recertification of specialists in order to improve their competence (Stevens 2006). Another strategy was to retake the initiative in determining standards by producing practice guidelines. Medically produced guidelines were not perceived as a threat by health care administrators. On the contrary, it was thought that physicians would more willingly accept standards presented as guarantors of professional quality rather than as tools of administrative cost control (Day, Klein, and Miller 1998).

A last and critical force for regulation and standardization was the rapid development of technologies. Following the massive investments in biomedical technology in the twenty years after World War II, the American government began moving toward "technology assessment," a concept developed in the mid-1960s by the U.S. House Subcommittee on Science, Research and Development (for an overview of the history of the field, see Banta 2003; Lehoux and Blume 2000). In the 1970s, the U.S. Environmental Protection Agency was created, reflecting widespread enthusiasm for regulatory bodies of all sorts. In the health sector, 
problems surrounding the Dalkon shield and defective cardiac pacemakers led to the Medical Devices Amendments of 1976 that effectively gave the U.S. Food and Drug Administration (FDA) the authority to regulate medical devices in a manner similar to its regulation of drugs. This was more than simple consumer protection. The FDA was also charged with overseeing the collection of data relating to the efficacy of such devices (Foote 1987). The FDA amendments had been preceded by the formation of the Office of Technology Assessment (OTA) in 1974 that included a special health program. These were followed by the NIH's Office of Medical Applications of Research in 1978 that initiated an ongoing series of consensus development conferences. Enthusiasm peaked in the late 1970s when, following the OTA's Report on the Development of Medical Technology, the U.S. Congress created the National Center for Health Care Technology in 1978. This federal agency was never funded properly and finally died an unseemly death in 1982. While other enterprises have followed and proved equally ill-fated-such as the Institute of Medicine's Committee to Plan a Private/Public Sector Entity to Assess Technology in Medical Care formed in 1983 (Institute of Medicine 1983, 1985) — there was no turning back. Biomedical technology has remained the constant target of containment and regulation (Altman and Blendon 1979; Nihom, Gillpatrick, and Wood 1994; Rettig 1994).

The NIH's Consensus Development Program was one of the more influential institutions to come out of this activity surrounding technology assessment, and it had a significant though indirect role in the spread of practice guidelines. This program was designed to evaluate and disseminate reliable knowledge about subjects thought to be controversial or problematic. Despite being a form of collective expertise, consensus meetings were innovative by virtue of their formalized structure, resulting in a widely disseminated consensus statement. In its first decade, more than sixty conferences were conducted and frequently were well publicized. Some, like the early-breast-cancer-screening conference of 1977, came to conclusions that had significant effects on health policy (Wortman, Vinokur, and Sechrest 1988). The creation of guidelines was not, however, part of the original mandate of the consensus program. Indeed, its proponents specifically differentiated technology assessment from practice guidelines, which they saw as growing more directly from the needs of the clinical community (Ferguson 1995). Nonetheless, consensus conferences constituted the first large-scale and ongoing 
governmental program using formalized decision-making procedures and designed to influence the practice of clinicians. Catalogers at the National Library of Medicine's PubMed certainly considered the reports generated by these conferences to be "practice guidelines." ${ }^{8}$ Consensus development became a model that many developed nations followed as a way of producing clinical guidelines (Giraud and Jolly 1991; Perry 1987).

The Consensus Development Program illustrates the multiple functions of guideline development. Some accounts of its creation focus on the perceived need to facilitate the dissemination of new technologies (Mullan and Jacoby 1985). Others (Perry 1987) emphasize the desire to control the health care costs of unproven technologies. ${ }^{9}$ These motivations probably varied at different times and for different individuals. Some of the earliest and most famous meetings, like the one on breast-cancer screening, served the traditional function of providing an expert evaluation of preventive public health measures. Finally, these conferences fulfilled an important scientific function. Although by now, clinical trials had become the standard for rigorous evaluation, they frequently did not provide unambiguous evidence of efficacy and required some form(s) of higher-level analysis in order to reach conclusions. Consensus conferences were meant to provide just this sort of service.

By the 1980s, guideline production and consensus conferences regularly took place in much of the Western world, with specialist associations now actively involved. In 1976 a number of specialist societies joined Blue Cross and Blue Shield's Medical Necessity Project, and in the next two years they identified seventy-six tests and procedures that were no longer medically justified (Woolf 1990). In 1981 the American College of Physicians introduced the Clinical Efficacy Assessment Project (CEAP) as a three-year grant, whose goals were to assemble and review the clinical literature on a specified topic, identify the best scientific papers, and reformulate such information so that practitioners could use it. Like the NIH's consensus program, this project initially focused on diagnostic tests and technologies but soon expanded to other practices and was given permanent status. ${ }^{10}$ Certainly, there was considerable medical resistance to the introduction of "cookbook medicine," but this was hardly sufficient to hold back the swelling tide. In 1990 more than thirty-five physician organizations and specialty societies were reported to have developed guidelines; the AMA and the Council of Medical Specialty Societies had endorsed practice guidelines and were organizing 
specialty societies to set policy for their development; and academic medical centers had formed a research consortium on practice guidelines (Woolf 1990).

By the beginning of the next decade, guidelines were ubiquitous enough for the National Library of Medicine's PubMed to add to its list of publication types the categories "Guidelines" in 1991 and "Practice Guidelines" a year later. American guidelines were produced by a wide array of public health, public and private research, and advocacy institutions, as well as by numerous specialist medical societies. To some degree this reflected the lack of a centralized power structure in the U.S. health care system. By contrast, the United Kingdom's first few guidelines were largely professional in origin. In a system in which the government controlled costs by setting low overall budgets and the National Health Service had far greater power to directly impose standardized procedures, professionals tried to make the most of the limited resources at their disposal (e.g., Royal College of Nursing 1975; Joint Working Party 1976). Later guidelines produced by experts were used to resolve controversial social-medical issues like appropriate therapies for drug addiction (Mars 2005). Prime Minister Margaret Thatcher's reforms of the 1980s made the control of costs and quality the direct responsibility of the government, thereby creating the need for national standards of evaluation and leading to a proliferation of guidelines starting in the 1990s (Day, Klein, and Miller 1998; Giaimo 2002).

In France, it has been argued, the impetus for guidelines came from a health bureaucracy desperate to bring greater control and coordination to the health care system. The process, it also has been suggested, has since been co-opted by the medical profession, even though guidelines have been produced by a single (albeit continually changing) state agency (Robelet 2002). But however one evaluates the relative power and authority of the groups involved in these activities, each nation's guidelines remain the product of complex relationships among multiple actors.

The development of guidelines, already a thriving activity by the mid1980s, has evolved considerably since then. In keeping with the many sources of guidelines in the United States, as well as the emphasis on making information available, the federal AHRQ joined the AMA and other institutions to create in 1990 the National Guidelines Clearinghouse. But in 1995 the AHRQ's very existence was seriously threatened when various groups objected to the participation of a government agency in 
actually drawing up guidelines. The agency saved itself by restricting its role to that of a guideline clearinghouse (Gray, Gusmano, and Collins 2003).

Other countries have succeeded in placing guidelines production under the aegis of national agencies, bringing together professional and administrative actors as well as experts in various disciplines: the $\mathrm{Na}-$ tional Institute for Clinical Excellence (NICE) in the United Kingdom, the Scottish Intercollegiate Guidelines Network (SIGN) in Scotland, the Ärztliches Zentrum für Qualität in der Medizin ( $\ddot{A Z Q})$ in Germany, and a succession of French agencies (most recently the Haute Autorité de santé). In Canada, where the provinces provide health care, the development of guidelines has been fragmented. The Canadian Medical Association plays a major coordinating role through its database of clinical guidelines. The mandate of these different institutions is to promote and standardize the guideline process, which has been uneven and eclectic, to say the least (Burgers et al. 2003).

The appearance of practice guidelines during the 1970s and 1980s preceded the evidence-based medicine (EBM) movement and remained grounded in traditional forms of authority, with experts, sometimes individually but frequently collectively, deciding on the best practices in a domain. In the case of consensus conferences, which began in the late 1970s, the authority of experts in different fields was supplemented by both consumer representatives and strict procedural protocols. The EBM movement of the 1990s-which emerged in academic medical institutions - went a step further by demanding that evaluation be based on distinctions among levels of evidence. At the summit of the evidence pyramid were randomized clinical trials (usually requiring meta-analyses to produce clear results). The original idea behind EBM was to teach doctors to examine the medical literature critically. Although not completely abandoned as an aim, it quickly became apparent that most doctors would not or could not directly evaluate the literature themselves. Digests of the most important articles or synthetic reviews that summarized a topic were prepared by the Cochrane Library and the ACP Journal Club, among others (Daly 2005). Such syntheses have gradually moved to increasingly short and uncomplicated guidelines that are supposed to be user-friendly enough to influence physicians' performance. This apparent abdication of clinical judgment has provoked unease even among some of the pioneers of EBM (Daly 2005). The collective expertise of specialty associations and the more formalized procedural rigor of 
consensus conferences continue to support much guideline development, but both seem to be in the process of being taken over by "evidence-based" procedures of evaluation. There now are guidelines for the production of guidelines (e.g., Eccles et al. 1996), as well as various protocols for grading guidelines according to quality (e.g., Guyatt et al. 2006).

The focus of the EBM movement on clinical efficacy, like the movement for medical safety set off by the much publicized report on medical errors published by the Institute of Medicine (1999), has somewhat undercut the cost-cutting rationale of guidelines, although it can be, and has been, argued that quality and safety save money in the long run. In recent years, the British National Health Service has pursued standardization and guideline development with a vengeance even as it has raised health-spending levels that were among the lowest in western Europe (Klein 2006). While some quarters of the medical profession have been hostile to guidelines, which they perceive as an attempt to promote "cookbook" medicine (Margo 2004; McNeil 2001), many have embraced them. This does not mean, however, that guidelines represent only, or even predominantly, the autonomous collective expertise of the medical profession. National agencies bring together administrators, statisticians, and medical researchers who may work with specialist societies but who also rely on multidisciplinary guideline-producing groups and institutions (e.g., Moreira 2005). In health care, the conditions are equally complex. For example, one study described American managed care organizations (MCOs) at the end of the twentieth century as follows:

All MCOs piggyback on guidelines produced by specialist societies or other prestigious bodies rather than creating their own.

- But all MCOs customise guidelines for their own plan use.

- Most plans use specialised management consultants for implementation. (Day, Klein, and Miller 1998, p. 65)

Like other elements of contemporary biomedicine, guidelines bring together numerous groups of actors arrayed in multiple and sometimes innovative permutations and combinations (e.g., Bourret 2005).

Although there certainly are real tensions around guidelines, they cannot be reduced to simple conflicts between administrators seeking to control costs and practitioners seeking to maintain autonomy. In most cases, such tensions cut across and divide professional groups. While they are committed to the most effective care for their patients, 
the medical producers of guidelines are beginning to take account of cost-effectiveness considerations (e.g., Bokemeyer et al. 2007; Lichtin 2005). Some medical groups are even establishing quality measures, and others are supporting fee incentives (Editorial 2006). For administrators, guidelines are undoubtedly part of an array of organizational techniques-incentives, monitoring, differential payments, and performance indicators - that are meant to modify doctors' practices and lower costs. Nonetheless, the evidence is growing that guidelines actually do increase the use of medications and consequently the cost of health care (e.g., Dubois and Dean 2006). It is quite likely that health administrators also have divergent perspectives, with some opposed to normative guidelines that would, in the final analysis, restrict their own sphere of action. ${ }^{11}$

In sum, the world of guidelines is an arena in which a growing number of groups (including patients) are trying to impose their own views of proper practice and in which both consensus and conflict frequently cut across occupational boundaries. Medical associations of every sort (including those representing other health care professions, notably nurses, dentists, and dieticians) are among the many players in this crowded domain. Guidelines, in other words, serve multiple functions for numerous groups. That is why they have become ubiquitous.

\section{Conclusion}

The current work on clinical practice guidelines focuses on their impact on the autonomy of physicians individually and collectively, on their cost-control functions, on how physicians use or do not use guidelines, and on finding more effective ways of disseminating them. We have attempted to broaden discussion of this subject by emphasizing the historical and sociological complexity of the processes that led to their emergence, particularly the wider movement that transformed medicine during the past century by introducing standards into the increasingly interrelated domains of public health, biomedical research, and clinical practice. The result has been a great rise in the number of domains that now require formal standards or informal conventions in order to function in acceptable ways. The pressure for guidelines thus has many sources: the recognition of and unhappiness with the variability of competence based on training and credentials; the need for protocols for the 
proper functioning of new research techniques and complex therapeutic technologies and procedures; and the demands for public accountability and standardized organizational procedures generated by the inclusion of more and more health care practices under the jurisdiction of large-scale public organizations. Depending on the circumstances, guidelines may protect against criticism, legal action (if followed), or efforts to contain costs, or they may promote all of these. In some cases, like cancer therapy, guidelines and protocols define entire domains, which simply could not function in their current form without them (Keating and Cambrosio 2007).

Clinical guidelines are hardly unique; health care now is inundated with guidelines of every sort. Long-term health planning; the establishment of new institutions or services; specialist training; the evaluation of medications, procedures, and technologies; laboratory testing; utilization management; and ethics review are only some of the activities that have produced an extensive guideline literature. And the list keeps getting longer. What all these activities have in common with cancer treatment protocols or multisite clinical trials is their technical complexity and need to coordinate large numbers of people and things. In addition to the growing scope and complexity of institutions and activities to be regulated, expectations have changed as well. As health care has become a public good financed by public monies, domains once characterized by individual judgment and idiosyncrasy have become increasingly subject to demands for transparency and regulation. And every effort to regulate increasingly unwieldy health care systems seems to produce complex mechanisms that require even more rules or conventions in order to function. Accordingly, we now have layer upon layer of guidelines and protocols. As was the case in the past, clinical guidelines remain closely linked to the many other forms of regulatory standardization that aim to bring order, predictability, and commensurability to an increasingly vast and heterogeneous domain.

\section{Endnotes}

1. By the late eighteenth century in France, the meteorological surveys of, for example, the Société royale de médecine required the extensive standardization of instruments, of ways of measuring them, and of forms for recording the results (Tournay 2007). Later, the Paris Academy of Medicine used a variety of approaches (usually unsuccessfully) to collect information from the networks of epidemics doctors and spa physicians under its jurisdiction (Weisz 1995). 
2. See the website of the International Federation of Gynecology and Obstetrics, http://www.figo .org (accessed February 2007).

3. The Food and Drug Act of 1906 was mainly concerned with the safety of foods and the fraudulent labeling of drugs. In 1938 the role of the FDA in regulating pharmaceuticals was expanded by the Federal Food, Drug, and Cosmetic Act to review drugs for safety before authorizing them for sale.

4. For instance, since 1997 Canada has had guidelines for how ethics boards should review clinical trials (Health Canada 1997).

5. These were the online catalogs of the National Library of Medicine; the university libraries of Harvard, Yale, and Columbia; Philadelphia College of Physicians and Surgeons; New York Academy of Medicine; British Library; Bibliothèque interuniversitaire de médecine, Paris; and Bibliothèque nationale (Paris).

6. The number of collectively produced guidelines in our sample of library catalogs (n. 5) published in the single decade after 1975 was higher than the number published during the previous thirty years (sixty-seven versus fifty-five). The more than 250 reports or discussions of collectively produced and clinically relevant guidelines that appeared during this decade can be identified from the titles in PubMed. A search for "practice guidelines" as a document type yielded forty-two entries published between 1979 and 1985, and 247 between 1986 and 1990 . These figures most likely underrepresent documents of this type, since they are based on a retrospective categorization of papers following PubMed's introduction of "practice guidelines" as a "document type" in 1992.

7. Among the more important ones were the professional standards review organizations (PSROs) discussed later; the Office of Technology Assessment (1974); and the health system agencies created as a result of the National Health Planning and Resources Development Act (1974).

8. Of the forty-two references published between 1979 and 1985 and classified as "practice guidelines" in PubMed, fourteen were associated with the Consensus Development Program.

9. Interviews with program participants conducted by Peter Keating produced equally divergent accounts of the original mission.

10. Website of the American College of Physicians, http://www.acponline.org/sci-policy/ guidelines/ceap.htm (accessed May 30, 2007).

11. May (2006), for instance, found that for precisely this reason, the local middle-level managers in the British National Health Service frequently are opposed to evidence-based health technology assessment.

\section{References}

Altman, S.H., and R. Blendon. 1979. Medical Technologies: The Culprit behind Health Care Costs? Proceedings of the 1977 Sun Valley Forum on National Health. Washington, D.C.: U.S. Government Printing Office.

American Academy of Pediatrics, Accident Prevention Committee. 1955. Accidental Poisoning in Childhood; a Reference-Guide to the Constituents of Common Household Substances Together with Treatment Recommendations for Their Accidental Ingestion by Children. Evanston, Ill.: Edward Press.

American Academy of Pediatrics, Committee on Fetus and Newborn. 1949. Standards and Recommendations for Hospital Care of Newborn Infants, Full-Term and Premature. Evanston, Ill. 
American Association of Medical Record Librarians (AAMRL). 1957. Proceedings of the Workshop on Standards and Procedures for Medical Records and Reports in Chronic Disease Hospitals, November 5-9, 1956, Washington, D.C. Chicago: AAMRL.

American College of Obstetricians and Gynecologists. 1959. Manual of Standards in Obstetric Gynecologic Practice. Chicago.

American College of Surgeons. 1931a. Committee on the Treatment of Fractures. An Outline of the Treatment of Fractures. Chicago.

American College of Surgeons. 1931b. Organization of Service for the Diagnosis and Treatment of Cancer, a Minimum Standard. Chicago.

American College of Surgeons. 1970. Guidelines for Cancer Care; Organization, Personnel, Facilities. Chicago.

American Heart Association. 1941. Standardization of Blood Pressure Readings; Joint Recommendations of the American Heart Association and the Cardiac Society of Great Britain and Ireland. New York.

American Heart Association. 1962. Recommended Standards for Cardiovascular Clinics; a Guide for Clinic Committees. 2d rev. ed. New York.

American Urological Association, Professional Relations Committee. 1968. Terminology and Relative Values of Urological Procedures: Report of a Study and Recommendations by the Professional Relations and Terminology Committees. 2d ed. Baltimore.

Armstrong, D. 2002. Clinical Autonomy, Individual and Collective: A Qualitative Study of Changing GPs' Behaviour. Social Science and Medicine 55:1771-77.

Banta, D. 2003. The Development of Health Technology Assessment. Health Policy 63:121-32.

Benamouzig, D. 2005. La santé au miroir de l'économie: Une bistoire de l'économie de la santé en France. Paris: Presses universitaires de France.

Berg, M. 1995. Turning a Practice into a Science: Reconceptualizing Postwar Medical Practice. Social Studies of Science 25:437-76.

Berg, M. 1997. Rationalizing Medical Work: Decision-Support Techniques and Medical Practices. Cambridge, Mass.: MIT Press.

Berg, M., K. Horstman, S. Plass, and M. Van Heusden. 2000. Guidelines, Professionals and the Production of Objectivity: Standardization and the Professionalism of Insurance Medicine. Sociology of Health and Illness 22:765-97.

Bertillon, J. 1895. Cours élémentaires de statistiques administrative. Paris: Société d'éditions scientifiques.

Bokemeyer, C., M.S. Aapro, A. Courdi, J. Foubert, H. Link, A. Osterborg, L. Repetto, and P. Soubeyran. 2007. EORTC Guidelines for the Use of Erythropoietic Proteins in Anaemic Patients with Cancer: 2006 Update. European Journal of Cancer 43(2):258-70. 
Bonah, C., É. Lepicard, and V. Roelcke, eds. 2003. La médecine expérimentale au tribunal: Implications éthiques de quelques procès médicaux au XXe siècle européen. Paris: Éditions des archives contemporaines.

Bonner, T.N. 1995. Becoming a Physician: Medical Education in Britain, France, Germany, and the United States, 1750-1945. New York: Oxford University Press.

Boston Board of Health. 1855. Sanitary Measures of the Board of Health (Boston), in Relation to Yellow Fever. Boston.

Bourret, P. 2005. BRCA Patients and Clinical Collectives: New Configurations of Action in Cancer Genetics Practices. Social Studies of Science 35:41-68.

Brussels Treaty Organisation. 1955. Recommendations and Conclusions on the Rebabilitation of the Disabled, 1948-1955. London.

Bryce, P.H. 1894. Report on Tuberculosis in Ontario, Presented to the Provincial Board of Health and Adopted with Recommendations Therein Contained. Toronto: Warwick Bros. \& Rutter.

Buchen, J.J. 1917. The Prevention of Venereal Disease: With Special Reference to the Report of the British Royal Commission on Venereal Diseases. Public Health 30:78-86.

Bullough, V.L. 1966. The Development of Medicine as a Profession: Medicine and the Medieval University. Basel, Switzerland: Karger Books.

Burgers, J.S., R. Grol, N.S. Klazinga, M. Makela, and J. Zaat. 2003. Towards Evidence-Based Clinical Practice: An International Survey of 18 Clinical Guideline Programs. International Journal of Quality Health Care 15:31-45.

Cambrosio, A., P. Keating, T. Schlich, and G. Weisz. 2006. Regulatory Objectivity and the Generation and Management of Evidence in Medicine. Social Science and Medicine 63:189-99.

Cantor, D. 2007. Introduction: Cancer Control and Prevention in the Twentieth Century. Bulletin of the History of Medicine 81:1-38.

Castel, P. 2002. Normaliser les pratiques, organiser les médecins: La qualité comme stratégie de changement, le cas les Centre de lutte contre le cancer. PhD diss., Institut d'études politiques de Paris.

Chicago Community Trust. 1922. A Community Trust Survey of Prenatal Care in Chicago: A Study of the Importance of Prenatal Care and of the Existing Facilities in Local Hospitals and Clinics, with an Outline of Standards and Some Recommendations, by Mrs. Kenneth F. Rich. Chicago.

Cochrane, A.L. 1972. Effectiveness and Efficiency: Random Reflections on Health Services. London: Nuffield Provincial Hospitals Trust.

Codman, E.A. 1925. Bone Sarcoma, an Interpretation of the Nomenclature Used by the Committee on the Registry of Bone Sarcoma of the American College of Surgeons. New York: Hoeber. 
College of Physicians of Ireland. 1853. Recommendations of the College of Physicians of Ireland Relative to the Prevention of an Outbreak of Cholera, and the Treatment of Its Earlier Stages. Dublin Quarterly Journal of Medical Science.

Committee on Insurance and Prepayment Plans. 1965. Guidelines for Establishing Medical Society Review Committees. Journal of the American Medical Association 194(9):1021.

Cook-Deegan, R., and M. McGeary. 2006. The Jewel in the Federal Crown? History, Politics, and the National Institutes of Health. In History and Health Policy in the United States: Putting the Past Back In, edited by R.A. Stevens, C.E. Rosenberg, and L.R. Burns, 176-201. New Brunswick, N.J.: Rutgers University Press.

Daly, J. 2005. Evidence-Based Medicine and the Search for a Science of Clinical Care. Berkeley: University of California Press/New York: Milbank Memorial Fund.

Day, P., R. Klein, and F. Miller. 1998. A Comparative US-UK Study of Guidelines. London: Nuffield Trust Series No. 4.

Dommann, M. 2006. From Danger to Risk: The Perception and Regulation of X-Rays in Switzerland, 1896-1970. In The Risks of Medical Innovation: Risk Perception and Assessment in Historical Context, edited by T. Schlich and U. Tröhler, 93-115. London: Routledge.

Dubin, M.D. 1995. The League of Nations Health Organisation. In International Health Organizations and Movements, 1918-1939, edited by P. Weindling, 56-80. Cambridge: Cambridge University Press.

Dubois, R.W., and B.B. Dean. 2006. Evolution of Clinical Practice Guidelines: Evidence Supporting Expanded Use of Medicines. Disease Management 9:210-23.

Durand-Zaleski, I., C. Colin, and C. Blum-Boisgard. 1997. An Attempt to Save Money Using Mandatory Practice Guidelines in France. British Medical Journal 315:943-46.

Eccles, M., Z. Clapp, J. Grimshaw, P.C. Adams, B. Higgins, I. Purves, and I. Russell. 1996. North of England Evidence Based Guidelines Development Project: Methods of Guideline Development. British Medical Journal 312:760-62.

Editorial. 2006. Paying Doctors for Better Care. New York Times, December 26. Available at http://www.nytimes.com/2006/12/26/opinion/ 26tue1. html? ex $=1189224000 \&$ en $=91 \mathrm{dec} 546 \mathrm{cf} 8 \mathrm{adeb} 0 \& \mathrm{ei}=5070$ (accessed September 12, 2007).

Eghigian, G. 2000. Making Security Social: Disability, Insurance, and the Birth of the Social Entitlement State in Germany. Ann Arbor: University of Michigan Press. 
Fagot-Largeault, A. 1989. Les causes de la mort: Histoire naturelle et facteurs de risque. Paris: Librairie philosophique J. Vrin.

Ferguson, J.H. 1995. Technology Transfer: Consensus and Participation-The NIH Consensus Development Program. Journal on Quality Improvement 21:332-36.

Foote, S.B. 1987. Assessing Medical Technology Assessment: Past, Present and Future. The Milbank Quarterly 65:59-80.

Fowkes, F.G., and C.J. Roberts. 1984. Introducing Guidelines into Clinical Practice. Effective Health Care 6:313-23.

Fox, D.M. 1979. Economists and Health Care: From Reform to Relativism. New York: Prodist.

Fox, D.M. 1986. Health Policies, Health Politics: The British and American Experience, 1911-1965. Princeton, N.J.: Princeton University Press.

Fox, D.M. 1996. From Piety to Platitudes to Pork: The Changing Politics of Health Workforce Policy. Journal of Health Politics, Policy and Law 21(1996):825-44.

Framingham Community Health and Tuberculosis Demonstration. 1918. Standards for the Diagnosis, Classification and Treatment of Pulmonary and Glandular Tuberculosis in Children and Adults. $3 \mathrm{~d}$ ed. Framingham, Mass.

France Cour des comptes. 2005. La sécurité sociale—Septembre 2005. Paris: Direction des journaux officiels.

Freidson, E. 1970. Profession of Medicine: A Study of the Sociology of Applied Knowledge. New York: Dodd, Mead.

General Recommendations of the National Laboratories for the Standardisation of X-Ray Dosemeters. 1934. British Journal of Radiology 7:304-8.

Giaimo, S. 2002. Markets and Medicine: The Politics of Health Care Reform in Britain, Germany, and the United States. Ann Arbor: University of Michigan Press.

Giraud, A., and D. Jolly. 1991. Le consensus en médicine: Analyse et bilan des conférences de consensus dans le monde. Paris: Assistance publique de Paris.

Gosselin, R. 1985. Probing into Task Interdependencies: The Case of Physicians in a Teaching Hospital. Journal of Management Studies 22:466-97.

Gradmann, C., and J. Simon, eds. 2008. Evaluating and Standardizing Therapeutic Agents 1890-1950. Houndmills, Basingstoke: Palgrave.

Gray, B.H. 1991. The Profit Motive and Patient Care: The Changing Accountability of Doctors and Hospitals. Cambridge, Mass.: Harvard University Press. 
Gray, B.H., M.K. Gusmano, and S.R. Collins. 2003. AHCPR and the Changing Politics of Health Services Research. Health Affairs Supplement, web exclusive: W3-283-307.

Guidelines for Organizing State and Area-Wide Community Health Planning. 1966. American Journal of Public Health/Nation's Health 56(12):2139-43.

Guyatt, G., D. Gutterman, M.H. Baumann, D. Addrizzo-Harris, E.M. Hylek, B. Phillips, G. Raskob, S. Zelman Lewis, and Holger Schünemann. 2006. Grading Strength of Recommendations and Quality of Evidence in Clinical Guidelines: Report from an American College of Chest Physicians Task Force. Chest 129:17481.

Hassenteufel, P. 1997. Les médecins face à l'état: Une comparaison européenne. Paris: Presses de la fondation nationale des sciences politiques.

Health Canada. 1997. Good Clinical Practice: Consolidated Guideline ICH Topic E6. Ottawa: Public Works and Government Services Canada. Available at http://www.hc-sc.gc.ca/dhp-mps/alt_formats/hpfb -dgpsa/pdf/prodpharma/e6_e.pdf (accessed March 17, 2007).

Health Commissioners Boston. 1832. Report and Recommendations of the Committee Appointed by the Health Commissioners of Boston, to Consider What Measures the Board Ought to Take for the Care and Treatment of the Sick, in Case the Cholera Should Appear in the City. J. Binney, chairman. Read, accepted and ordered to be printed June 25, 1832.

Healy, D. 1997. The Antidepressant Era. Cambridge, Mass.: Harvard University Press.

Holman, W.L., O.T. Avery, R.A. Kinsella, and J.H. Brown. 1918. Recommendations of the Committee on a Standard Routine Method for the Isolation and Identification of Hemolytic Streptococci from Throats Sputa, and Pathologic Exudates. Journal of Laboratory and Clinical Medicine 3:618-21.

Howell, J.D. 1995. Technology in the Hospital: Transforming Patient Care in the Early Twentieth Century. Baltimore: Johns Hopkins University Press.

Indiana Polio Planning Committee. 1950. Recommendations on Nursing Procedures and Techniques in Hospitals Treating Poliomyelitis Cases. Indianapolis: Indiana State Board of Health.

Institute of Medicine. 1983. A Consortium for Assessing Medical Technology. Washington, D.C.: National Academy Press.

Institute of Medicine. 1985. Assessing Medical Technologies. Washington, D.C.: National Academy Press.

Institute of Medicine. 1989. Controlling Costs and Changing Patient Care? The Role of Utilization Management. Washington, D.C.: National Academy Press. 
Institute of Medicine. 1999. To Err Is Human: Building a Safer Health System. Washington, D.C.: National Academy Press.

Iowa State Medical Society. 1948. Cancer Committee Standards for the Diagnosis and Treatment of Cancer. Iowa City.

Jasanoff, S. 1990. The Fifth Branch: Science Advisers as Policymakers. Cambridge, Mass.: Harvard University Press.

Johnson, T.J. 1972. Professions and Power. London: Macmillan.

Joint Working Party of the Royal College of Physicians of London and the British Cardiac Society. 1976. Prevention of Coronary Heart Disease: Report of a Joint Working Party of the Royal College of Physicians of London and the British Cardiac Society. London.

Keating, P., and A. Cambrosio. 2007. Cancer Clinical Trials: The Emergence and Development of a New Style of Practice. Bulletin of the History of Medicine 81:197-223.

Klein, R. 2006. The Troubled Transformation of Britain's National Health Service. New England Journal of Medicine 355:409-15.

Larson, M.S. 1977. The Rise of Professionalism: A Sociological Analysis. Berkeley and Los Angeles: University of California Press.

Lehoux, P., and S. Blume. 2000. Technology Assessment and the Sociopolitics of Health Technologies. Journal of Health Politics, Policy and Law 25:1083-1120.

Lichtin, A. 2005. The ASH/ASCO Clinical Guidelines on the Use of Erythropoietin. Best Practices of Resident Clinics of Haematology 18(3):43338.

Margo, C. 2004. Quality Care and Practice Variation: The Roles of Practice Guidelines and Public Profiles. Survey of Ophthalmology 49:35971.

Marks, H.M. 1997. The Progress of Experiment: Science and Therapeutic Reform in the United States, 1900-1990. Cambridge: Cambridge University Press.

Marks, H.M. 2006. "Until the Sun of Science... The True Apollo of Medicine Has Risen": Collective Investigation in Britain and America, 1880-1910. Medical History 50:147-66.

Mars, S. 2005. Peer Pressure or Imposed Consensus? The Making of the 1984 Guidelines of Good Clinical Practice in the Treatment of Drug Misuse Making Health Policy. In Networks in Research and Policy after 1945, edited by V. Berridge., 149-84. Amsterdam: Rodopi.

Massachusetts Department of Public Health. 1931. Minimum Standards for the Diagnosis, Treatment and Control of Gonorrbea, Approved by the Committee on Public Health of the Massachusetts Medical Society and by the Neisserian Medical Society of Massachusetts. Prepared by the Massachusetts Department of Public Health co-operating with the United States Public Health Service (Boston). 
May, C. 2006. Mobilising Modern Facts: Health Technology Assessment and the Politics of Evidence. Sociology of Health E Illness 28(5):51332.

Mazumdar, P.M.H. 2003. "In the Silence of the Laboratory": The League of Nations Standardizes Syphilis Tests. Social History of Medicine $16: 437-59$.

McNeil, B.J. 2001. Hidden Barriers to Improvement in the Quality of Care. New England Journal of Medicine 345:1612-20.

McPherson, K., and J.P. Bunker. 2006. Costs, Risks and Benefits of Surgery: A Milestone in the Development of Health Services Research. James Lind Library. Available at www.jameslindlibrary.org (accessed January 28, 2007).

Moreira, T. 2005. Diversity in Clinical Guidelines: The Role of Repertoires of Evaluation. Social Science \& Medicine 60:1975-85.

Mullan, F. 2004. Wrestling with Variation: An Interview with Jack Wennberg. Health Affairs. Web exclusive available at http://content. healthaffairs.org/webexclusives/index.dtl year $=2004$ (accessed September 6, 2007).

Mullan, F., and I. Jacoby. 1985. The Town Meeting for Technology: The Maturation of Consensus Conferences. Journal of the American Medical Association 254(8):1068-72.

Nachlas, M.M. 1991. Irrationality in the Management of Breast Cancer. I. The Staging System. Cancer 68:681-90.

National Tuberculosis Association. 1920. Standards for the Diagnosis and Classification of Tuberculosis. New York.

National Tuberculosis Association. 1955. Diagnostic Standards and Classification of Tuberculosis. New York: Committee on Revision of Diagnostic Standards, American Trudeau Society.

Nelkin, D. 1995. Science Controversies: The Dynamics of Public Disputes in the United States. In Handbook of Science and Technology Studies, edited by S. Jasanoff, G.E. Markle, J.C. Petersen, and T. Pinch, 444-56. Thousand Oaks, Calif.: Sage.

Nihom, J., T.R. Gillpatrick, and V.R. Wood. 1994. Health Care Cost Containment: Rationing Medical Technology. Journal of Ambulatory Care Mark 5:57-68.

Nowak, R. 1994. Problems in Clinical Trials Go Far beyond Misconduct. Science 264:1538-41.

Perry, S. 1987. The NIH Consensus Development Program. A Decade Later. New England Journal of Medicine 317(8):485-88.

Physicians' Guidelines for Delegation of Duties and Functions to Nurses. 1966. Wisconsin Medical Journal 65(1):26-27.

Pinell, P. 2002. The Fight against Cancer: France 1890-1940. Translated from French by D. Madell. London: Routledge. 
Porter, D., ed. 1994. The History of Public Health and the Modern State. Atlanta: Rodopi.

Radiological Treatment of Cancer. Recommendations on Standards and Technique. 1929. The Lancet 2:348-51.

Rettig, R.A. 1994. Medical Innovation Duels Cost-Containment. Health Affairs 13(3):7-27.

Reverby, S. 1981. Stealing the Golden Eggs: Ernest Amory Codman and the Science and Management of Medicine. Bulletin of the History of Medicine 55:156-71.

Robelet, M. 2002. Les figures de la qualité des soins: Rationalisation et normalisation dans une économie de la qualité. PhD diss., Université Aix-Marseille II.

Roentgen Society. 1915. London Recommendations for the Protection of $X$-Ray Operators. London.

Rosen, G. 1976. The Efficiency Criterion in Medical Care, 1900-1920: An Early Approach to an Evaluation of Health Service. Bulletin of the History of Medicine 50:28-44.

Rothman, D.J. 1991. Strangers at the Bedside: A History of How Law and Bioethics Transformed Medical Decision Making. New York: Basic Books.

Royal College of Nursing of the United Kingdom. 1975. Improving Geriatric Care in Hospital: Report of a Working Party of the British Geriatrics Society and Royal College of Nursing of the United Kingdom. London.

Ruger, U., and K. Bell. 2004. Historische Entwicklung und aktueller Stand der Richtlinien-Psychotherapie in Deutschland [The Historic Evolution and Actual Status of Psychotherapy Practice Guidelines in Germany]. Zeitschrift für Psychosomatische Medizin und Psychotherapie 50(2):127-52.

Schlich, T. 2002. Surgery, Science and Industry: A Revolution in Fracture Care, 1950s-1990s. Houndsmills, Basingstoke: Palgrave.

Schlich, T. 2007. The Art and Science of Surgery: Innovation and Concepts of Medical Practice in Operative Fracture Care, 1960s-1970s. Science, Technology and Human Values 32:65-87.

Sinding, C. 2002. Making the Unit of Insulin: Standards, Clinical Work, and Industry, 1920-1925. Bulletin of the History of Medicine 76(2):231-70.

Stevens, R.A. 1989. In Sickness and in Wealth: American Hospitals in the Twentieth Century. New York: Basic Books.

Stevens, R.A. 2006. Specialization as American Health Policy: Interweaving Public and Private Roles. In History and Health Policy in the United States, edited by R.A. Stevens, C.E. Rosenberg, and L.R. Burns, 49-82. New Brunswick, N.J.: Rutgers University Press. 
Timmermans, S., and M. Berg. 2003. The Gold Standard: The Challenge of Evidence-Based Medicine and Standardization in Health Care. Philadelphia: Temple University Press.

Timmermans, S., and E.S. Kolker. 2004. Evidence-Based Medicine and the Reconfiguration of Medical Knowledge. Journal of Health and Social Behavior 45(extra issue):177-93.

Tournay, V. 2006. De la bioéthique à l'action publique en matière de biotechnologie: La production des thérapies cellulaires. Cabiers internationaux de sociologie 121:265-86.

Tournay, V. 2007. Produire l'objectivité médicale: Un système expérimental réplicatif de standardisation. Sociologie du travail 49:253-67.

U.S. Children's Bureau. 1934. Standards of Prenatal Care. An Outline for the Use of Physicians. Bureau publication no. 153 (rev.). Washington, D.C.: U.S. Government Printing Office.

U.S. Children's Bureau. 1943. Standards and Recommendations for Hospital Care of Newborn Infants, Full-Term and Premature. Title Publication No. 292: Washington, D.C.

U.S. Veterans Administration. 1949. Protocols for the Treatment of Tuberculosis by SM, DHSM, and PASS. Washington, D.C.

Wangensteen, O.H. 1978. Surgery and Surgical Travel Groups. Surgery, Gynecology and Obstetrics 147:246-54.

Webster, C. 1988. The Health Services since the War. Vol. 1, Problems of Health Care: The National Health Service before 1957. London: Her Majesty's Stationery Office.

Weisz, G. 1995. The Medical Mandarins: The French Academy of Medicine in the Nineteenth and Early Twentieth Centuries. New York: Oxford University Press.

Weisz, G. 2006. Divide and Conquer: A Comparative History of Medical Specialization. Oxford: Oxford University Press.

Wennberg, J.E. 1979. Factors Governing Utilization of Hospital Services. Hospital Practice 14(9):115-21, 126-27.

Wennberg, J., and A. Gittelsohn. 1973. Small Area Variations in Health Care Delivery. Science 182(117):1102-8.

Wiener, C.L. 2000. The Elusive Quest: Accountability in Hospitals. Hawthorne, N.Y.: De Gruyter.

Wilde, S. 2004. See One, Do One, Modify One: Prostate Surgery in the 1930s. Medical History 48:351-66.

Wilson, M. 1993. DSM-III and the Transformation of American Psychiatry: A History. American Journal of Psychiatry 150:399-410.

Woolf, S.H. 1990. Practice Guidelines: A New Reality in Medicine. I. Recent Developments. Archives of Internal Medicine 150(9):1811-18. 
Wortman, P.M., A. Vinokur, and L. Sechrest. 1988. Do Consensus Conferences Work? A Process Evaluation of the NIH Consensus Development Program. Journal of Health Politics, Policy and Law 13:46998.

Acknowledgments: Research for this paper was supported by grants from the Canadian Institutes of Health Research (CIHR MOP-64372) and the Fonds québécois de la recherche sur la société et la culture (FQRSC ER-95786). 